\title{
Rumo a uma etnografia da música contemporânea. Prólogo para um projeto de investigação
}

Towards an Ethnography of New Music: Prologue to a Research Project

Vers une ethnographie de la musique contemporaine. Prologue pour un projet de recherche

\section{Gil Fesch}

\section{OpenEdition}

\section{Journals}

Edição electrónica

URL: http://journals.openedition.org/rccs/6260

DOl: $10.4000 /$ rccs. 6260

ISSN: 2182-7435

\section{Editora}

Centro de Estudos Sociais da Universidade de Coimbra

Edição impressa

Data de publição: 1 Maio 2016

Paginação: 163-184

ISSN: 0254-1106

\section{Refêrencia eletrónica}

Gil Fesch, «Rumo a uma etnografia da música contemporânea. Prólogo para um projeto de investigação », Revista Crítica de Ciências Sociais [Online], 109 | 2016, colocado online no dia 18 maio 2016, criado a 03 maio 2019. URL : http://journals.openedition.org/rccs/6260 ; DOI : 10.4000/ rccs. 6260 


\section{GIL FESCH}

\section{Rumo a uma etnografia da música contemporânea. Prólogo para um projeto de investigação*}

O presente artigo avança com uma discussão preliminar acerca dos fundamentos teóricos que servem de base a um projeto de investigação em curso. Para tal, desvelar-se-á a estratégia de aproximação ao objeto de estudo - o Remix Ensemble Casa da Música -, oferecendo, assim, um quadro de análise que permita dar passos rumo a um retrato do subcampo da música contemporânea portuguesa, e que possibilite uma leitura crítica da tão propalada crise da nova música. Desenreda-se a exposição em torno de quatro eixos fundamentais: 1) breve problematização da evolução histórica da sociologia da música; 2) esboço de modelo teórico, assente numa proposta de diálogo entre conceitos-chave (campo e mundo artístico); 3) revisão (sumaríssima) de literatura específica e do papel da etnografia; e 4) análise da problemática e definição dos objetivos específicos.

Palavras-chave: Howard Becker (1928-); música contemporânea; Pierre Bourdieu (1930-2002); sociologia da música; teoria sociológica.

\section{Introdução: a evolução paradigmática da sociologia da música}

Outrora terreno baldio, malpropício à empresa sociológica, a música é hoje tomada como espaço privilegiado para pensar fenómenos coletivos. ${ }^{1}$ E os motivos para que tal aconteça são fortes. Senão, veja-se: sabemos do potencial que o estudo da esfera simbólica, das manifestações culturais e da densa cadeia do sentido tem para nos reenviar - de maneira mais ou menos clara, mas invariavelmente rica - para a (co)produção da subjetividade, para

\footnotetext{
* Este trabalho contou com o apoio da Fundação para a Ciência e a Tecnologia, através da bolsa de doutoramento com a referência SFRH/BD/98528/2013 - projeto realizado sob a orientação científica do Professor Doutor João Teixeira Lopes e da Professora Doutora Paula Guerra. Tratando-se de uma investigação em curso, o texto que aqui se apresenta assume um caráter naturalmente preliminar; pretende-se, pois, debater o trajeto percorrido, articulando apoios teóricos, opções metodológicas e objetivos de pesquisa.

${ }^{1}$ Importa sublinhar, sem prejuízo do exposto, que a música sempre assim foi reputada (e disso é prova o legado de alguns dos clássicos da disciplina), mas encontramos, em anos recentes, crescente entusiasmo face às oportunidades por ela oferecidas à investigação sociológica.
} 
a intimidade mediada dos sujeitos, e, como tal, para o domínio das práticas sociais. E que outra forma tão particularmente expressiva, afetiva e inclusiva, que não a música, para cumprir o propósito?

Adianta Lahire (2003: 21) que toda a teoria sociológica da ação e do ator tem subjacente, independentemente da sua natureza, a busca pela "fórmula geradora das suas práticas" - ou fórmulas (as "molas da ação"). É pois precisamente na questão de número que a contenda se processa: fórmula ou fórmulas? Sujeito enquanto ente reflexivo e industrioso, ou mero recetáculo de influências, verticalmente dúctil? Também na música, por isso, a discussão é delimitada por dois grandes polos: o da "unicidade do ator e o da sua fragmentação interna". E é neste equilíbrio de forças, delicado, entre tradições teóricas, que se joga o desenvolvimento teórico-metodológico da sociologia da música, articulado num processo sucessório que levou a mudanças substanciais em termos de abordagem $e$ objeto.

Tornou-se, então, habitual pensar a evolução paradigmática da sociologia da música de forma bietápica (e.g., Martin, 2006; Hennion, 2002). À tal metanarrativa totalizante, projeto de teoria estética que carrega a indelével assinatura de Adorno, reagiam modernas perspetivas sociológicas, relativamente indiferentes perante a obra artística ensimesmada (music itself), e apostadas em situar a experiência estética no seu contexto social mais vasto. Não mais passavam a ser tolerados discursos teleológicos (ou proselíticos sequer) acerca da passividade dos públicos - amparados, até então, pela análise textual -, abandonava-se o apadrinhamento teórico da musicologia, e rumava-se a uma plena consagração sociológica da música, agora considerada na sua multidimensionalidade.

Mais do que um simples panegírico à subjetividade, este afastamento sistemático do "foco estruturalista" - que entendia a música como uma "espécie de espelho da estrutura social" (Guerra, 2015a: 5) - tem, assim, por base uma abertura do espectro da análise à música popular ${ }^{2}$ (sobretudo pela via etnográfica e histórico-etnográfica), num reconhecimento cabal do seu potencial "constitutivo e relacional, conflitual e performativo" (Prior, 2008: 302). ${ }^{3}$ Alijada do compromisso ascético - forte pressuposto do projeto modernista -, esta 'nova' sociologia da música passava a debruçar-se sobre

\footnotetext{
2 Ao mobilizar o termo 'música popular', estamos, naturalmente, conscientes da ambiguidade que lhe é inerente (albergando manifestações culturais tão distintas como a música tradicional, a música comercial ou de massas, entre outras). Por manifesta impossibilidade prática, a discussão terminológica não pode ser enfrentada aqui, mas importa tornar claro que nos afastamos de qualquer tipo de conceção hierarquizante. Move-nos a simples utilidade analítica. Para uma discussão alargada, vide Dubois (2011).

3 Todas as traduções presentes no texto são da responsabilidade do autor.
} 
questões tão diversas como as complexas redes colaborativas que sustentam os meios artísticos (Becker, 1982), putativas homologias entre géneros musicais e estilos de vida de grupos sociais específicos (Willis, 1978), o papel das instâncias de legitimação, mercados de trabalho e carreiras artísticas (Menger, 1999), os processos de mediação tecnológica (Hennion, 2002) ou as experiências e usos quotidianos da música (DeNora, 2000).

Muitos foram, portanto, os contributos desta nova vaga de abordagens contextuais que, desvinculadas esteticamente, propunham formas alternativas de conceptualizar as coletividades musicais. Novas e evanescentes práticas artísticas colocavam desafios teóricos que exigiam, por sua vez, flexibilidade e dinamismo metodológicos. À rigidez das propostas dos subculturalistas (e.g., Hebdige, 1979) - naquela que era uma primeira tentativa de renovação teórica, ainda que de inspiração marxista, assente num léxico estruturalista e classista, que superestima a coerência dos grupos (Hesmondhalgh, 2005) -, sobrevinham novas terminologias. DiMaggio (1987) insistia no conceito de género, cuja polissemia permitia apresentar sistemas de classificação artística como construções multidimensionais e dinâmicas; Bennett (1999) avançava com o conceito de tribo, num esforço sustentado para repensar a relação entre juventude, estilo e gosto musical; Straw (2006) contrapunha a ideia de cena, enriquecendo o estudo da música popular com o aporte teórico da geografia cultural. ${ }^{4}$

Se os méritos destas propostas são hoje amplamente reconhecidos (Guerra, 2015b), acompanhando a efervescência das manifestações culturais e desierarquizando saberes, é também facto que substituíram uma forma de soberania teórica por outra. A música popular vê-se justamente valorizada, tida como área de indiscutível interesse teórico, mas consegue-o, em parte, às custas do seu eterno émulo. Não surpreende, assim, que escasseiem, entre os recentes avanços conceptuais, soluções analíticas que conduzam a um modelo teórico aplicável à música 'erudita' (em especial à criação 'contemporânea') - i.e., alternativas que permitam dar resposta epistemológica aos conhecidos impasses da tradição sociológica. Como ultrapassar, então, antinomias clássicas entre perspetivas estruturalistas e individualistas da música? Como conciliar níveis de análise? E como responder aos sucessivos apelos à interdisciplinaridade (e.g., Born, 2010a; Boia, 2015)? Que papel reservar à abordagem contextual? Será possível (ou até pertinente) reintegrar o objeto estético na abordagem contextual, evitando assim novas formas de ortodoxia? Começaremos agora por reconsiderar criticamente a genealogia da disciplina.

\footnotetext{
${ }^{4}$ Não podendo este trabalho, por razões evidentes, abraçar a disputa enunciada, remete-se para a análise crítica de Hesmondhalgh (2005).
} 


\section{De regresso às fundações}

A cristalização de linhas mutuamente exclusivas, ter-se-á tornado claro, fazia-se na oposição crispada entre texto e contexto, da teoria para a empiria, oscilando entre objeto e sujeito. Como nos diz Born (2010b: 173), é hoje dado assumido que "a sociologia da arte se definiu, em grande medida, por oposição à estética, quer desconstruindo pretensões autonómicas da arte, quer analisando as determinações sociais e históricas da experiência estética". Constituíam-se, então, as vias teórica, "desenhando homologias entre a arte e as suas condições sócio-históricas”, e empirista, atenta às "práticas, tecnologias, convenções e divisão do trabalho", numa contenda que encorajava, em idêntica medida, progressos e imprecisões. Firmada ao eixo aristotélico episteme-tékhne, a disputa desmontava distopias clássicas, enquanto se encobriam nuances e ligações.

Por esse motivo se argumentou, em parte outra, ${ }^{5}$ que a visão panorâmica agora esboçada (correspondente ao posicionamento generalizado de teóricos recentes face à literatura clássica), embora de inquestionável utilidade analítica, assenta frequentemente em leituras parciais destes contributos. Aí se propunha um modelo de leitura alternativo, de confrontação dialética, em que se reconheciam, a reboque de Teixeira Lopes (2000), tanto a ambiguidade conceptual da sua produção teórica (nas suas titubeações, apostas e retrocessos), como a complexidade, abrangência e atualidade do seu pensamento.

Weber, a título de exemplo, precipita o desenvolvimento de correntes teóricas como o interacionismo simbólico ou o individualismo metodológico, através da noção de 'ação social', mas é igualmente acusado, no que à música diz respeito (Weber, 1998), de propor uma abstração despessoalizante. Glorifica-se-lhe o princípio de 'neutralidade sociológica' - pedra basilar do moderno pensamento teórico -, à medida que se ataca o compromisso estético e a ocidentalidade da sua visão. ${ }^{6}$ A sua obra funde-se, assim, com a de Simmel, ambas influenciadas pela teoria marxista, kantianas na sua essência, mas diverge epistemologicamente, no método e sistematicidade. Junta-se a Adorno na perspetiva macro: partilham um modelo analítico em que sociedade e música surgem espelhadas.

\footnotetext{
${ }^{5}$ Para uma proposta de itinerário teórico da sociologia da música, vide Fesch (2015). Não se pretendia considerar na íntegra a genealogia da disciplina, mas tão-somente sugerir uma grelha de leitura alternativa, que considerasse de maneira diacrónica as plataformas de diálogo e protolinhagens teóricas estabelecidas entre autores clássicos.

${ }^{6}$ Parte destas incongruências justificar-se-á com leituras isoladas da sua teoria social lato sensu e da sua produção especificamente dedicada à música. Reitera-se, por conseguinte, a necessidade de integrar o nível particular no contexto da obra completa, neste e noutros autores.
} 
Já Simmel, uma vez reconhecido o desalinho do seu programa, espanta pela atualidade do pensamento: o duplo olhar que convoca perante os fenómenos sociais, pressuposto metodológico decisivo da sua proposta, funda uma postura de relativismo analítico que hoje assume centralidade nas ciências sociais. Insiste, com Adorno, que a música cria os seus próprios universos de sentido (Simmel, 1968), acessíveis apenas aos culturalmente iniciados, e possibilita, simultaneamente, a sensibilidade benjaminiana. Antecipa Hennion na mediação tecnológica, permite Becker, pela atenção prestada à interação social.

Em Benjamin (2010), por sua vez, honra-se a experiência sensório-corporal, abrindo alas a um discurso teórico dignificador de formas culturais 'menores' e, por conseguinte, a correntes teóricas como a dos cultural studies. Apesar do tom pessimista, encontramos aqui um importante entreabrir de porta, deambulando entre espaço intelectual e emocional, estética e anestética entrecruzadas num enobrecimento hegeliano da subjetividade, das respostas sentimentais, da nostalgia e da melancolia. Nas suas páginas encontramos, por isso, locução fronteiriça a outras tradições, arrojada no recurso à figura de estilo, ao jogo de palavras, ou a uma certa ambiguidade de registo que tanta largura permite à sociologia.

Adorno (1991), esse, marca a agenda teórica ao não hesitar na necessidade de considerar sociologicamente o texto (que é musical). Mas é talvez o seu método dialético - recorrentemente tomado como algo absoluto e, por isso mesmo, incompreendido - o seu contributo mais relevante: incita-nos a proceder por contradição, exagerando os termos e iluminando implicações. Torna-se, assim, explícita a tensão entre opostos, e o todo inteligível (Paddison, 1982). Devidamente controlada nos seus excessos, expurgada do nojo trágico em face do anunciado destino da cultura ocidental, a dialética adorniana (Adorno, 1994) constitui, assim, um importante apoio teórico - justapondo sociologia, musicologia e filosofia - e (questão mais sensível, porventura) metodológico também.

Mas consideremos novamente a plataforma teórica estabelecida entre Weber e Simmel. Os respetivos projetos constituíam-se em frutuoso diálogo, ainda que mais ou menos implícito, em complementar antonímia - eis a chave. Reconhecendo tratar-se de uma micro-oposição - se considerarmos a totalidade do espaço teórico -, o anseio literário (senão lírico) de Simmel, um quase pontilhismo teórico, encontra o seu reverso epistemológico na sistematicidade weberiana; a formulação metafísica da individualidade, do primeiro, contrastando com a proposta, defendida pelo segundo, de integração do sujeito num processo histórico mais vasto, de racionalização da sociedade ocidental. Vislumbram-se, neste primeiro confronto dialético, 
no choque entre análise sistemática e ensaísmo ou forma aberta, entre macro-história e psicossociologia, as bases de contendas vindouras.

Se Simmel reconhece validade aos discursos dos atores sociais, ao sentido que atribuem às próprias ações, Weber entende que a motivação interna é parte ínfima de uma constelação ampla de fenómenos, acessível apenas pela interseção de causalidades múltiplas, evitando, assim, equívocos metodológicos e possíveis parcelamentos da realidade social. A análise não se propõe, evidentemente, exaustiva, ${ }^{7}$ mas importa salientar que é neste subtil (se bem que expressivo) desentendimento epistemológico que se circunscrevem as condições de debates futuros - não uma genealogia em sentido literal, mas tímidas germinações, os alicerces teóricos que possibilitam a moderna abordagem científica dos fenómenos simbólicos.

\section{Da (im)possibilidade de articulação conceptual}

Supra abraçávamos a discussão matricial da disciplina - unicidade versus fragmentação. Posto de outra forma, duas grandes tendências: uma que atribui peso excessivo ao passado (de que são exemplo a teoria crítica, ou a teoria psicanalítica) e outra que tudo explica com base no momento da ação (pensemos no individualismo metodológico, interacionismo simbólico, etnometodologia, grounded theory, etc.). As mesmas implicações subjazem às propostas teóricas de Bourdieu e Becker, que aqui prolongam o debate. Nomos interior, "disposição incorporada", ou "acontecimento desencadeador" como determinante das práticas? Em ambos os casos - e este é o aspeto relevante -, trata-se de uma escolha a priori, postulado e não hipótese, i.e., falamos de posturas analíticas baseadas "mais em pressupostos éticos do que em constatações empíricas” (Lahire, 2003: 21). A denúncia é de Lahire, a quem nos juntamos na recusa, que é dupla, da "fórmula", "sistema", ou "princípio unificadores, mas também $[\mathrm{d}] \mathrm{a}$ fragmentação generalizada ou [d] o fraccionamento disseminador" (ibidem: 29).

Entende-se, por isso, importante mobilizar as duas teses - em concreto os conceitos de campo e mundo artístico -, como forma de 1) promover uma aproximação à problemática ancorada numa postura de relativismo

\footnotetext{
${ }^{7}$ O leitor informado estranhará o aparente esquecimento de autores relevantes - como são os casos de Herbert Spencer ou John Mueller, mas principalmente de Alfred Schütz. O seu célebre texto - "Making Music Together: A Study in Social Relationship" - e em especial os conceitos aí propostos, de inner time ou mutual tuning-in relationship, constituíram uma importantíssima inspiração para interacionistas como Becker ou Faulkner, entre outros (Shepherd e Devine, 2015: 24). Relembra-se, no entanto, que o objetivo expresso desta secção passava não por uma revisão extensiva da literatura clássica da disciplina, mas antes por esboçar um modelo alternativo de leitura, que contemplasse discussões teóricas relevantes.
} 
analítico, de inspiração simmeliana, ciente dos perigos em que uma e outra incorrem, prevenindo-nos, assim, de ver, na realidade social, unicamente aquilo que procuramos, mantendo-nos alerta para possibilidades inesperadas; e 2) porque se entende que, também do ponto de vista da operacionalização, ambos os conceitos são compatíveis, apesar das (ou justamente pelas) diferenças epistemológicas/metodológicas.

Quando falamos em campo, referimo-nos a um processo histórico de diferenciação entre esferas de atividade, enquanto campos sociais relativamente autónomos - espaços estruturados de posições, com diferentes doxai, investimentos, recompensas, interesses e lógicas. Dito de outra forma, uma 'topologia social' (Born, 2010b: 177) constituída através da tomada de posição (competitiva, ainda que complementar) e delimitada por trajetórias possíveis. Falamos, então, de lutas específicas aos campos, cujo motor seria a distribuição desigual de capitais, e, por isso, de uma teoria dos campos de poder (Wacquant, 2005: 118). Bourdieu coloca, assim, a arte numa teia de relações sociais para explicar que a transcendentalidade é afinal produto da crença coletiva - a ideia de illusio -, transformando, em última instância, a obra artística em fetiche, pelo que ao sociólogo caberia desvendar a desigualdade estrutural dos campos artísticos, acobertada pelas práticas (aparentemente) desinteressadas (Prior, 2011: 124).

Mas os campos não esgotam, sabemo-lo, a interação social. Dizem respeito, fundamentalmente, ao domínio das atividades profissionais (e públi-cas). A própria autonomia dos campos - por muito que cada universo (e.g., artístico, literário, científico) tenda a extremá-la - não pode senão ser considerada relativamente, uma vez que há reconhecida sobreposição de (ou permeabilidade entre) esferas, com natural preponderância do campo económico. Há agentes sem interesse nas lutas, há campos que são subcampos de outros campos, há práticas e objetos que pertencem a vários campos simultaneamente, agentes entre e sem campos (Lahire, 2003: 43-44). É por isso que encontramos contextos sociais que congregam agentes 'profissionais', 'legítimos' ou 'permanentes', mas igualmente 'amadores', simples 'consumidores' e 'espectadores'. Mais: assumir que os agentes lutam entre si não deve, ainda assim, impedir-nos de reconhecer que, em nome do interesse específico do campo, existe entre eles um certo grau de "cumplicidade objetiva" que vai para além das lutas que os opõem (Lahire, 2001: 25).

As brechas da teoria bourdiana são, pois, evidentes: negligencia (ou pelo menos desprestigia) a dimensão sensório-corporal da cultura, sobrevaloriza a experiência estética em moldes sociológicos e falha em conceptualizar a mudança (Prior, 2008: 312). Por isso se propõe que a teoria 
dos campos seja vista como uma ferramenta de inquestionável utilidade analítica, que permite responder a uma série de problemas científicos, mas sem com isso esquecer que pode, por sua vez, constituir um sério obstáculo ao conhecimento do mundo social, sobretudo quando tomada como instrumento exclusivo para a contextualização das práticas (Lahire, 2001: 36).

É, portanto, indispensável complementar o mapeamento das posições inerentes ao campo (ou subcampo) com uma análise mais fina, sensível às nuances da interação social, atenta a subjetividades múltiplas, que contemple lógicas de ação colaborativa - no fundo, analisar não só indivíduos concretos, nomeados, mas também as relações por eles estabelecidas. É disso exemplo a teoria dos art worlds (Becker, 1982): ao evitar ascender à abstração bourdiana - a separação quase esquizofrénica entre campo e um tal universo de relações pessoais entre agentes do campo -, e focando, em vez, na interação social - i.e., nos mecanismos que permitem a emergência das práticas artísticas (Bottero e Crossley, 2011: 100) -, mostra-se, no que a este ponto concerne, evidentemente mais promissora. A ênfase atribuída à relação entre convenção (musical) e prazer, a título ilustrativo, é particularmente importante, ao oferecer alternativa à noção de illusio - a tal "crença colectiva nas regras do jogo" (Teixeira Lopes, 2003: 88) como forma de explicar o compromisso com a atividade cultural, sem para isso mobilizar forçosamente lutas simbólicas ou o instrumentalismo (Crossley e Bottero, 2015). Eis, então, por que motivo se entende que a associação imediata entre campo e habitus, quando pensada rigidamente, nos impede de analisar uma vastidão de práticas sociais.

Por outro lado, e sendo certo que Becker marca a atualidade ao olhar para as redes que enformam os diversos meios musicais, despoluindo o debate teórico, é igualmente evidente que falha em enquadrar a experiência subjetiva na estrutura de relações objetivas. Referimo-nos, claro está, à crítica recorrente segundo a qual a teoria beckeriana (e o interacionismo de forma geral) negligencia questões estruturais de poder e de recursos. (Sublinhe-se, em boa verdade, que tais questões são também cruciais em Becker; simplesmente não são enfrentadas do ponto de vista estrutural.) A sua abordagem é, assim, interacional no seu sentido mais vasto: os mundos artísticos fazem-se não pelo estrito contacto entre atores sociais, mas através das redes e dos sistemas de ligações, diretos e indiretos (Bottero e Crossley, 2011: 105). Encerra-se, como tal, numa certa ingenuidade analítica, cegando-se ante lógicas competitivas, de luta pela imposição, por parte de grupos sociais específicos, de taxonomias favoráveis, de esquemas classificatórios que reproduzam e/ou alterem a estrutura dominante. 
Dir-se-á, em suma, que se a teoria dos campos não pode fazer mais do que estudar a "dimensão polemológica dos universos considerados" (Lahire, 2001: 43), menoscabando simultaneamente história de longa duração e microssociologia (cujos objetos são tomados como questões marginais, insignificantes), o conceito de art world - e seus sucedâneos, de que é exemplo a noção de culture world (Crane, 1992) -, ao convocar os mais diversos pilares das manifestações culturais (produtores, convenções, instâncias de legitimação, organizações, públicos, etc.), e reinscrevendo-as no seu contexto, pode assumir-se como um importante contraponto, que nos permite abraçar a especificidade da comunicação artística, e, assim, enrique-cer a proposta de Bourdieu. É neste quadro que a abordagem contextual beckeriana assume particular relevância para o nosso programa de pesquisa: vinculando decisivamente a produção do sentido ao encontro entre obra e recetores, sejam eles detentores dos códigos culturais 'legítimos' ou não. Como afirma Lahire, impõe-se consagrar que:

a progressiva autonomização das funções sociais [...] está indissociavelmente ligada ao processo de constituição de tradições específicas, continuamente re-tomadas, trans-formadas, re-elaboradas, de geração em geração, e que formam uma base para a elaboração de lógicas, de objetos, e de estilos de enunciação cada vez mais específicos. (2001: 41)

Será, no entanto, legítimo questionar a exequibilidade de uma proposta que visa mobilizar conceitos com implicações tão distintas como os de campo e mundo artístico. Se a possibilidade de considerá-los conjuntamente no plano teórico, ao bom estilo da dialética adorniana, encontrará - pensamos - pouca resistência, a ideia de conceber um desenho metodológico que congregue os dois será decerto algo mais controverso. De pronto justificamos: pensadas de forma complementar, as duas noções podem unir-se numa arquitetura que contemple vários níveis de análise, i.e., apontando a uma sociologia pluriescalar, que recuse um modelo causal da ação humana. Num tal desenho, a perspetiva de Becker adequar-se-ia, de um modo geral, a uma escala micro, realçando quadros normativos, modos de fazer partilhados, crenças e valores a que os atores aderem, prestando-se o conceito de campo tendencialmente à dimensão meso, ao enquadrar estes mesmos mundos artísticos num espaço social mais vasto, de posições fortemente estruturadas, sujeito à participação em disputas sistémicas pela propriedade simbólica, de que nos fala Bourdieu.

Urge, ainda assim, salientar, sem prejuízo do exposto, que a proposta agora desenhada não faz uma absoluta separação entre níveis de análise 
- e, como tal, dos respetivos conceitos, algo que significaria reincidir no impasse da distinção entre estrutura e interação. As propostas teóricas de Bourdieu e Becker, aliás, e como terá ficado claro, não respondem a contextos diferentes; debruçam-se, isso sim, sobre aspetos distintos de uma mesma realidade social. Ambos os autores enfatizam, por exemplo, a fluidez da organização social e das práticas coletivas - como expresso na correspondência (parcial) entre a oposição bourdiana 'heterodoxia vs. ortodoxia', ou 'produtores tradicionais vs. vanguardistas' (Bourdieu, 1984), e a tipologia social de artistas proposta por Becker, que inclui 'profissionais integrados' e 'mavericks' (Becker, 1976). Os atores detêm recursos, interagem e formam relações; não parece, então, haver contradição entre as duas propostas (Bottero e Crossley, 2011: 114). Enquanto desconstruções sociologicamente informadas da doutrina kantiana, empenhadas em enquadrar o "objeto estético numa rede de forças e determinações sociais” (Prior, 2011: 122), há pois um potencial de complementaridade teórica que devemos explorar. Se a teoria dos campos assume um papel essencial na representação dos mecanismos e espaços em que se exercem os jogos de poder, é através de Becker que entendemos a complexidade das interações e a importância das redes colaborativas, contribuindo decisivamente para abarcar uma multitude de práticas sociais. Trata-se, por conseguinte, de reconhecer que, dentro de cada um destes contextos ou níveis de análise, e apesar de potenciais preponderâncias, coexistem lógicas e registos de ação plurais.

Começa agora a fechar-se o nosso quadro teórico que, não obstante, se mantém incapaz de responder a fenómenos de pertença simultânea a contextos sociais distintos, que exigem, por sua vez, diferentes esquemas de ação por parte de cada ator. É por isso que se assume, de novo com Lahire, que a subjetividade não se faz necessariamente por "síntese e unificação". Sem que se assuma uma lógica de total descontinuidade entre contextos de interação, consagra-se a possibilidade de incorporação de uma multiplicidade de esquemas de ação (de perceção, de avaliação, etc.), articulados em reportórios de esquemas de ação - conjuntos abreviados de experiências sociais, construídos e incorporados ao longo de socializações anteriores. Assim se coordenam passado e presente, enfrentando-se a realidade de forma relacional - a ação como ponto de encontro de experiências passadas e situação social presente -, ou seja, circunscrevendo os campos de ativação e inibição do passado incorporado, como proposto por Lahire. Acrescendo a Weber, postula-se, então, a necessidade de atender à pluralidade dos tempos e das lógicas de ação, i.e., de rumar a uma "sociologia da pluralidade das lógicas efectivas de acção e da pluralidade das formas de relação com a acção" (Lahire, 2003: 201). 
Esperamos agora estar finalmente em condições de corresponder à recomendação feita por Bourdieu (que de resto deixou por cumprir) e ir além de uma estéril "física social", durkheimiana, sem, para isso, recorrer a uma "semiologia social", cativa de "relatos de narrativas", encerrada em incongruentes depoimentos, mero "produto de estruturas mentais/linguísticas" (Bourdieu, 1984: 483). Insiste-se, pois, na "necessidade de conjugarmos perspectivas sociologistas com abordagens compreensivas, respeitando o poder de facticidade externa dos fenómenos sociais, mas rejeitando um papel de autómatos passivos aos agentes sociais” (Teixeira Lopes, 2000: 77).

\section{A música contemporânea e a etnografia institucional}

Chegados a este ponto, é então momento de restringir o âmbito da análise à problemática que nos ocupa - o cisma estético do modernismo musical e "a divergência sem precedentes entre a música contemporânea séria e os seus públicos” (Babbitt, 1958: 154). Como assevera Boulez, as obras musicais do nosso tempo tendem a assumir-se como eventos únicos - que têm, naturalmente, antecedentes, mas que são cada vez menos redutíveis a esquemas de perceção preestabelecidos -, criando evidentes obstáculos ao pronto discernimento e, como tal, alterando os requisitos necessários a uma plena imersão no nexo artístico, à relação com o objeto estético. Existem, portanto, bloqueios de código importantes, que diminuem as hipóteses de uma apropriação competente - ainda que "a força da mensagem, a qualidade da escrita, a beleza do som, [ou] a inteligibilidade das pistas" (Foucault e Boulez, 1985: 10) possam deflagrar situações de ligação espontânea. A questão da "insularidade cultural" da música de hoje, propunha Foucault (ibidem: 11), é pois mais complexa do que talvez nos tenha parecido à primeira vista; é consequência (não só) de uma deficiente pedagogia, ou de problemas de divulgação, mas também condição inexorável da própria criação contemporânea. Não mais gramática definida a posteriori - i.e., baseada numa teoria explanatória que é resultado de uma experiência coletiva de longo termo, como em Rameau -, falamos, sobretudo desde Stockhausen, em conhecimento desenvolvido a priori (Deliège, 2010: 157) - música que desafia convencionalismos, "que se liberta de todos os seus esquemas [e] sinais", "que não tenta ser familiar", "que não se repete a si mesma", "desenhada para preservar o seu caráter vanguardista” (Foucault e Boulez, 1985: 9, 11), pelo que espaço incontornavelmente fronteiriço.

O exposto é tão mais relevante se pensarmos que não se restringe a questões percetivas, ou de quadros de julgamento. É sabido que a praxis da música contemporânea convoca "técnicas instrumentais inovadoras, formas alternativas de notação, [e sobretudo] uma capacidade de adaptação 
a novas circunstâncias de performance" (ibidem: 7), fatores estes que negoceiam tendências antinómicas, de libertação e coerção, que, por sua vez, se traduzem em importantes oportunidades e constrangimentos para os mais diversos agentes que participam da esfera artística, que abalam o edifício tecnológico e burocrático que lhe está subjacente. Não espanta, por conseguinte, que tenhamos passado de "um problema real, a desadequação dos critérios tradicionais de avaliação e julgamento da arte atual, para diatribes político-ideológicas" (Jimenez, 2010: 250). Abre-se, então, caminho à condenação da produção contemporânea, tendo por base imposições de legitimidade e relevância artística, sem que nos apercebamos verdadeiramente da contradição aqui implícita.

O espaço não nos permite, por razões que serão evidentes, assumir uma discussão alargada, mas importa, em todo o caso, e se atentarmos ao panorama atual da programação artística e cultural, salientar a evidente primazia da lógica cultural sobre a estética. É, pois, cada vez mais difícil à arte contemporânea contornar as estruturas organizativas, de que é subsidiária, num processo que, em última instância, coloca em causa esse mesmo caráter subversivo que sempre a caracterizou (ibidem: 255). Começará, presumimos, a tornar-se clara a pertinência de alocar o debate ao contexto institucional, enquanto forma privilegiada de articular algumas das tensões referidas, para tal convocando a miríade de atores envolvidos. É por isso que, partindo das propostas seminais de Pierre-Michel Menger e Georgina Born, avançamos agora para a concretização da disputa teórica, reportando ao caso específico do centro IRCAM - instituição de particular relevância para o nosso objeto de estudo. ${ }^{8}$

Menger monta um verdadeiro aparato estatístico para denunciar aquilo que entende ser o progressivo fortalecimento da criação musical culta, no seu movimento de autonomização, através da formação de um mercado da inovação totalmente subvencionado. Beneficiando do processo histórico de canonização musical (Weber, 2003), legitima-se, de acordo com o autor, o apoio público à música contemporânea, pela criação de uma forma ímpar de protetorado cultural (Menger, 2001). À medida em que avança com a descrição detalhada das profundas transformações operadas no

\footnotetext{
${ }_{8}$ O Institut de Recherche et Coordination Acoustique Musique (IRCAM) é hoje um dos principais centros europeus de criação musical contemporânea e investigação científica. Fundado por Pierre Boulez durante os anos 70, em Paris - desde 2006 sob a direção de Frank Madlener -, está associado ao Centre Pompidou e é tutelado pelo Ministério da Cultura e da Comunicação. A atividade do IRCAM desenvolve-se em torno de três eixos fundamentais - criação artística, pesquisa tecnológica e divulgação científica -, tendo ainda ligação estreita com o Ensemble Intercontemporain. É, conjuntamente com a Casa da Música, membro do Réseau Varèse. Fonte: www.ircam.fr.
} 
mercado musical, à época, torna-se clara a "socialização progressiva dos riscos da atividade criadora" (ibidem: 27), no que a esta manifestação cultural diz respeito, por via do mecenato de Estado. Para tal, cruza o estudo das carreiras artísticas e caracterização sociográfica dos compositores de música 'séria' - sinalizando uma "homologia entre perfis de carreira, de um lado, e produção e tomadas de posição estética, do outro” (Héran, 1984: 315) -, com a análise pormenorizada da estrutura e comportamentos da procura.

Fala-nos, então, de uma 'hiperseleção' dos públicos - alto grau de familiaridade com a cultura musical clássica, posse de um importante capital escolar e pertença maioritária a classes superiores (Menger, 1988: 113) - e de uma equivalência autofágica entre produção e consumo, que resultam numa acentuação de traços distintivos de desigualdade na assistência. Mas Menger vai mais além nas conclusões: distingue entre consumo e perceção, e revela-nos, assim, o desfasamento entre "competência cultural suposta" e "competência estética demonstrada” (ibidem: 109). É por isso que questiona, em última instância, a aparente correspondência entre produção e con-sumo de bens culturais, ao detetar comportamentos de autocensura estética e forte voluntarismo disposicional por parte dos públicos. De acordo com o autor, a ausência de paradigmas dominantes na composição - i.e., a extrema fragmentação da produção, pela ação simultânea da individualização da sintaxe e do desenvolvimento anómico das investigações sobre os materiais sonoros - deu origem a uma "frustração percetiva generalizada" (ibidem: 137): o interesse pela música contemporânea parece, então, carecer de sustentação crítica. Assim entendidas, a continuidade na assistência e a auto-culpabilização ou voluntarismo na hora de aderir à estética vanguardista não poderiam senão associar-se a fenómenos de distinção social (Menger, 2001).

Georgina Born (1995), por sua vez, leva a cabo uma abordagem etnográfica que examina as práticas e os conhecimentos híbridos desenvolvidos através da colaboração entre músicos e cientistas informáticos. Dito de outra forma, retrata a progressiva racionalização do vanguardismo musical pós-serialista - ulterior fase do processo de burocratização que em Weber se delineara -, articulado em três vértices: o recurso à ciência e tecnologia, como forma de renovar a composição musical; a sua institucionalização, assente numa divisão alargada do trabalho; e o "policiamento" da estética autorizada (e consequente externalização e/ou negação de estilos musicais alternativos, ou de divergentes tecnologias [Born, 2010b: 189]). Entende, então, a autora que a administração do IRCAM, ao erguer tais barreiras, apontou a um controlo severo do tipo de música praticado na instituição, assegurando, dessa forma, o prolongamento da estética bouleziana. Contrariando autores que 
encontram na pós-modernidade a superação (ou pelo menos pacificação) de velhas tensões entre culturas erudita e popular, Born insiste numa forte consolidação do ethos modernista, reificado até pela própria linguagem pós-modernista - em seu entender, uma encarnação de decíduos antagonismos em relação a formas culturais 'menores'. Propõe, assim, uma linha de leitura que coordena subjetividades individuais e processos coletivos: através da análise de material histórico e etnográfico, filtrado pela teoria kleiniana, desmonta os mecanismos utilizados pela instituição para resistir às pressões políticas e comerciais, de modo a preservar a sua autonomia. Ao 'socializar' a sua conceção dos sistemas psíquicos, socorre-se, em suma, da herança antropológica para problematizar subjetividades autorais e estéticas (Born, 1997).

Falamos, então, de contributos teóricos que exigem mesura, que muito fizeram por recuperar avitas preocupações da sociologia, mas que não deixam, por isso, de convidar à crítica. Se a tradição clássica foi (devidamente) atacada por impor uma visão redutora da experiência estética, é também verdade que Menger pouco faz para nobilitar a 'procura'. Os da banda da teoria crítica levaram, é certo, a ideia de 'receção' a um ponto extremo, dramatizando as implicações da alegada passividade dos públicos, mas a proposta que agora se discute encerra problemas não menos significativos. Refere-se à 'herança das vanguardas' - conjunto de proibições fundamentais ditadas pela rutura com a tradição tonal -, mas igualmente a um estado de 'anomia estética' (Menger, 1988: 143), sem explorar devidamente a aparente contradição entre a alusão a uma tal inclinação estética comum (relembre-se que a rejeição é também fator de agregação e forma de delimitação) e a suposta ausência de paradigmas dominantes na composição, reflexo de uma pluralidade (ou fragmentação) disposicional.

Já em Born, procede-se sofregamente para a antinomia entre modernismo musical e música popular (na sua forma direta ou indireta - emulada pelo ecletismo pós-modernista), numa exacerbação abusiva dos princípios estéticos que sustentam uma e outra (negação/assunção da tonalidade, da repetição, da regularidade rítmica, assim como de formas musicais temáticas/narrativas). É por isso que, ao ignorar nuances no discurso de Boulez - estranhamente excluído das entrevistas -, e embarcando até em imprecisões terminológicas (como a utilização indistinta dos termos dodecafonismo e serialismo), Born vicia a denúncia da criação de um suposto enclave institucional privilegiado, formalista e elitista. Examina incongruências inter- e intrasubjetivas, avançando perigosamente numa psicologização da sociologia, em que mudanças nas disposições estéticas dos atores são entendidas necessariamente como calculismo estratégico, 
justificado pela busca de legitimidade, ou constrangimento incorporado, naturalizado, inconsciente (Born, 1997). Born sentencia, então, o contraste entre a superfície da retórica modernista - enfatizando a inovação, mudança e liberdade - e a estrutura profunda do discurso, inerte, codificado no fundo, atado a um conjunto limitado de práticas estéticas e opções teóricas, mas sobretudo a importantes proibições. Fará, no entanto, sentido falar-se de uma ontologia modernista, assente na retórica da inovação estética, e de uma filosofia IRCAM, de caráter "anti-inventivo" (Born, 2010b: 197)?

Os perigos são axiomáticos e, como tal, particularmente instrutivos para a perspetiva que aqui se fundamenta. Reconhecer a necessidade eminentemente sociológica de apontar a uma certa redução da complexidade da realidade social não deve impedir-nos de consagrar também zonas cinzentas, subtilezas e gradações, evitando, assim, a estéril alternância entre diferentes formas de determinismo e anomia. Eis então exposto um dos vícios da sociologia: a dialética sem relativismo. Como nos diz Lahire, a teoria sociológica tende a mergulhar-nos numa obrigatoriedade quase paralisante de escolha entre "a ordem da estratégia consciente, do cálculo, da decisão racional, da reflexividade ou da intencionalidade consciente”, e o "mundo do ajustamento pré-reflexivo, infraconsciente às situações práticas, do sentido prático e do sentido de improvisação" (Lahire, 2003: 201). E o que dizer do cruzamento interdisciplinar? A complementaridade entre tradições teóricas é elemento-chave de uma renovação metodológica que em muito contribuiu para ultrapassar ancestrais impasses epistemológicos, mas não pode implicar uma descaracterização da disciplina.

É por isso que, seguindo as pisadas de Born (2010b), e de acordo com a proposta que temos vindo a avançar, se propõe uma abordagem que integre a etnografia institucional numa análise mais abrangente, do (sub)campo de produção cultural em que opera - o modernismo musical -, mas que combine igualmente etnografia e história - i.e., que considere as diversas dinâmicas (discursiva, estética, política e económica) que informam o presente, consubstanciando as respetivas estratégias de mediação. Defende-se, por conseguinte, uma abordagem multimodal, material e imaterial, em que sujeitos e objetos coincidem - sujeito e obra considerados ao longo do tempo e espaço (Born: 2010b: 188). Só assim estaremos em condições de desenvolver uma interpretação crítica do objeto cultural em questão, respondendo de forma cautelosa ao apelo interdisciplinar, i.e., apostando numa beterodoxia controlada (Teixeira Lopes, 2000: 76), que dê:

particular atenção analítica aos factores que melhor exteriorizam a (relativa) autonomia da ordem cultural na multidimensionalidade do espaço social, designadamente 
a construção simbólica, as múltiplas linguagens e formas expressivas (com especial destaque para a hexis corporal), os rituais e todas as formas de representação e de ideação. (ibidem: 77)

\section{Perspetivas de pesquisa}

Este foi, portanto, o ponto de partida para o objeto de estudo - o Remix Ensemble Casa da Música -, na expectativa de contribuir para um retrato sociológico da música contemporânea no Porto, descortinando alguns dos complexos princípios que organizam este meio. E são vários os motivos de interesse. Desde logo, teórico-metodológicos: apontar a um apaziguamento entre correntes teóricas que nos permita, não recentrar, mas pelo menos restituir, à obra musical, dignidade analítica. Sabemos, desde Bourdieu, que a análise histórica "permite compreender as condições da 'compreensão', apropriação simbólica, real ou fictícia, de um objeto simbólico que pode acompanhar-se dessa forma particular de fruição [a] que chamamos estética" (Bourdieu, 1996:365). Não espanta, por isso, que haja pródromos, entre teóricos atuais (Born, 2010b; Hennion, 2002), de um reconhecimento crescente face às virtualidades da análise textual, da necessidade de pensar os fenómenos musicais por referência aos seus universos de sentido e de atender aos discursos estéticos. Só assim estaremos em condições de ultrapassar a eterna dicotomia entre universalismos descredibilizados e um total relativismo - reconciliando a abordagem sociológica com a experiência estética. Mais: a possibilidade de aplicar alguns dos recentes desenvolvimentos teórico-metodológicos, operados pela mão da cultura popular, à música 'erudita'. Por outras palavras, a oportunidade de submeter a abordagem contextual a um teste de abrangência, aplicando-a a um mundo artístico com evidentes especificidades.

Como nota Stubbs (2009), se a arte e arquitetura são hoje verdadeiros casos de sucesso mediático, escapando (a espaços) até à dura lógica dos mercados, o mesmo não se pode dizer da música contemporânea, que vai acumulando falhanços sucessivos, cujas propostas parecem afugentar o ouvinte comum. O vanguardismo parece ser bem-recebido no domínio das artes plásticas, que aliás muito partilham com as homólogas performativas, mas a verdade é que a experimentação musical embate na aparente indiferença dos públicos. Um mundo que mantém, para usurpar a expressão de Wacquant (2004: 17), uma "dupla relação de simbiose e oposição" face à música 'clássica', de afinidade e concomitante antagonismo, usufruindo da proteção legitimadora da estética pura, mas acabando por cair vítima de uma obsessiva ligação ao passado, da cristalização hagiográfica. Em todo o caso, a chave para entender o baixo grau de identificação dos 
públicos - e de boa parte dos músicos também - poderá estar também na formalidade e hermetismo, nas rígidas modalidades de fruição de um género musical marcado por ímpares lógicas simbólicas, que obedecem (ainda que no limite da acessibilidade) a uma fortíssima estruturação hierárquica. Em suma, e parafraseando Foucault (Foucault e Boulez, 1985), a questão não passa por perguntar, com a música a esta distância, como podemos repatriá-la, mas antes entender por que motivo, sendo-nos tão próxima, tão consubstancial à nossa cultura e ao nosso tempo, nos parece tão longínqua.

É, por isso, particularmente relevante cruzar representações de músicos e públicos, encontrar coincidências e descontinuidades face às opções institucionais, i.e., considerar conjuntamente os diversos planos da análise - produção, receção e mediação. Eis, então, corroborada a opção pela etnografia, pensada não como um fim em si (o tal pressuposto ético que carece de constatação empírica), mas antes como forma de aproximação ao terreno, de conciliação de níveis de análise e de articulação entre técnicas de recolha de dados. No fundo, tomada como elemento agregador das várias estratégias de pesquisa. Dado que o tema foi ainda muito pouco explorado pela sociologia, ${ }^{9}$ o objetivo passa por representar holística e heuristicamente este mundo artístico - fazer o levantamento do terreno e, assim, contribuir para a discussão informada.

Para tal, o Remix Ensemble é caso único no país, enquanto ensemble desta natureza - ou seja, de caráter institucional. Oferece, pois, condições ideais para 1) analisar redes de instituições culturais, a nível europeu, como são o Réseau Varèse ou a ECHO, 2) pensar a política cultural portuguesa, em especial modalidades mistas de financiamento (lógicas público-privadas), 3) retratar percursos educativos e formativos, 4) olhar para o mercado de trabalho e carreiras profissionais/artísticas, 5) avaliar estratégias de mediação cultural, 6) procurar perfis sociológicos dos públicos e entender os problemas de receção da música contemporânea, 7) reconstituir representações e subjetividades estéticas, 8) refletir sobre alterações profundas nas convenções musicais e nos modos de apropriação artística, entre outros.

Tudo isto enquanto celebramos o $10 .^{\circ}$ aniversário da Casa da Música e o $15 .^{\circ}$ do Remix, a que se junta a simbólica escolha da Alemanha como

\footnotetext{
9 Menção é devida aos textos inaugurais de Vieira de Carvalho (2007), sobre a tragédia da escuta na contemporaneidade, e de Pinho Vargas (2007), acerca da ausência da música portuguesa no contexto europeu - ambos partindo do prisma da teoria crítica. Refere-se ainda a exemplaridade do trabalho de Guerra (2013), naquele que é um contributo decisivo para a notoriedade da análise dos fenómenos musicais no seio da sociologia portuguesa.
} 
país homenageado na programação de 2015 , num momento em que ainda se sentem os efeitos de uma conjuntura económica e financeira que todos conhecemos - algo que acentua a pertinência da articulação com questões de política cultural, ou das lógicas de globalização. Altura privilegiada, portanto, para reconstituirmos a memória coletiva de um ensemble que alterou de forma profunda o panorama cultural português, para refletir e projetar tempos vindouros.

\section{Referências bibliográficas}

Adorno, Theodor (1991), The Culture Industry. New York: Routledge.

Adorno, Theodor (1994), Introduction à la sociologie de la musique. Genève: Éditions Contrechamps.

Babbitt, Milton (1958), "Who Cares if You Listen?", High Fidelity, 8(2), 154-159.

Becker, Howard (1976), "Art Worlds and Social Types”, American Behavioral Scientist, 19(6), 703-718.

Becker, Howard (1982), Art Worlds. Berkeley: University of California Press.

Benjamin, Walter (2010), "The Work of Art in the Age of its Technological Reproducibility", Grey Room, 39, 11-37.

Bennett, Andy (1999), "Subcultures or Neo-tribes? Rethinking the Relationship between Youth, Style and Musical Taste", Sociology, 33(3), 599-617.

Boia, Pedro dos Santos (2015), "Das tensões entre desmistificar e reconhecer os discursos ao repensar 'o social': manifesto por uma sociologia ecléctica”, Sociologia - Revista da Faculdade de Letras da Universidade do Porto, 29, 105-128.

Born, Georgina (1995), Rationalizing Culture: IRCAM, Boulez, and the Institutionalization of the Musical Avant-Garde. Berkeley: University of California Press.

Born, Georgina (1997), "Modernist Discourse, Psychic Forms and Agency: Aesthetic Subjectivities at IRCAM”, Cultural Antbropology, 12(4), 480-501.

Born, Georgina (2010a), "For a Relational Musicology: Music and Interdisciplinarity, Beyond the Practice Turn", Journal of the Royal Musical Association, 135(2), 205-243.

Born, Georgina (2010b), "The Social and the Aesthetic: For a Post-Bourdieuian Theory of Cultural Production”, Cultural Sociology, 4(2), 171-208.

Bottero, Wendy; Crossley, Nick (2011), "Worlds, Fields and Networks: Becker, Bourdieu and the Structures of Social Relations”, Cultural Sociology, 5(1), 99-119.

Bourdieu, Pierre (1984), Distinction: A Social Critique of the Judgement of Taste. Harvard: Routledge \& Keegan Paul Ltd.

Bourdieu, Pierre (1996), As regras da arte. Gênese e estrutura do campo literário. São Paulo: Companhia das Letras. 
Crane, Diana (1992), The Production of Culture: Media and the Urban Arts. California: Sage Publications.

Crossley, Nick; Bottero, Wendy (2015), "Music Worlds and Internal Goods: The Role of Convention”, Cultural Sociology, 9(1), 38-55.

Deliège, Célestin (2010), “A Period of Confrontation: The Post-Webern Years”, in Max Paddison; Irène Deliège (orgs.), Contemporary Music: Theoretical and Philosophical Perspectives. Surrey: Ashgate, 143-172.

Denora, Tia (2000), Music in Everyday Life. Cambridge: Cambridge University Press.

Dimaggio, Paul (1987), "Classification in Art”, American Sociological Review, 52(4), 440-455.

Dubois, Vincent (2011), "Lowbrow Culture and French Cultural Policy: The Socio-political Logics of a Changing and Paradoxical Relationship", International Journal of Cultural Policy, 17(4), 394-404.

Fesch, Gil (2015), "A sociologia da música e os seus fundadores: para uma reapreciação diacrónica”, in Paula Guerra (org.), More Than Loud: os mundos dentro de cada som. Porto: Afrontamento, 35-47.

Foucault, Michel; Boulez, Pierre (1985), "Contemporary Music and the Public", Perspectives of New Music, 24(1), 6-12.

Guerra, Paula (2013), A instável leveza do rock. Génese, dinâmica e consolidação do rock. alternativo em Portugal (1980-2010). Porto: Afrontamento.

Guerra, Paula (2015a), "Sonhos Pop: criação, aura e carisma na música moderna portuguesa”, E-Compós, 18(1), 1-22.

Guerra, Paula (2015b), “Introdução aos mundos dentro de cada som”, in Paula Guerra (org.), More Than Loud: os mundos dentro de cada som. Porto: Afrontamento, 7-26.

Hebdige, Dick (1979), Subculture: The Meaning of Style. London: Methuen.

Hennion, Antoine (2002), "Music and Mediation: Towards a New Sociology of Music", in Martin Clayton; Trevor Herbert; Richard Middleton (orgs.), The Cultural Study of Music: A Critical Introduction. London: Routledge, 80-91.

Héran, François (1984), "Menger (Pierre-Michel), Le paradoxe du musicien. Le compositeur, le mélomane et l'État dans la société contemporaine”, Revue française de sociologie, 25(2), 313-316.

Hesmondhalgh, David (2005), "Subcultures, Scenes or Tribes? None of the Above", Journal of Youth Studies, 8(1), 21-40.

Jimenez, Marc (2010), “Towards an Aesthetics of Risk”, in Max Paddison; Irène Deliège (orgs.), Contemporary Music: Theoretical and Philosophical Perspectives. Surrey: Ashgate, 249-258.

Lahire, Bernard (2001), “Champ, hors-champ, contrechamp”, in Bernard Lahire (org.), Le travail sociologique de Pierre Bourdieu: dettes et critiques. Paris: La Découverte, 23-57.

Lahire, Bernard (2003), O homem plural. Lisboa: Instituto Piaget.

Martin, Peter (2006), Music and the Sociological Gaze. Art Worlds and Cultural Production. Manchester: Manchester University Press. 
Menger, Pierre-Michel (2001), Le paradoxe du musicien. Le compositeur, le mélomane et l'État dans la société contemporaine. Paris: L'Harmattan.

Menger, Pierre-Michel (1988), "El oído especulativo. Consumo y percepción de la música contemporánea”, Papers Revista de Sociología, 29.

Menger, Pierre-Michel (1999), “Artistic Labor Markets and Careers”, Annual Review of Sociology, 25, 541-574.

Paddison, Max (1982), "The Critique Criticised: Adorno and Popular Music”, Popular Music, 2, 201-218.

Pinho Vargas, António (2007), "A ausência da música portuguesa no contexto europeu: Uma investigação em curso", Revista Crítica de Ciências Sociais, 78, 47-69.

Prior, Nick (2008), "Putting a Glitch in the Field: Bourdieu, Actor Network Theory and Contemporary Music”, Cultural Sociology, 2(3), 301-319.

Prior, Nick (2011), "Critique and Renewal in the Sociology of Music: Bourdieu and Beyond”, Cultural Sociology, 5(1), 121-138.

Shepherd, John; Devine, Kyle (2015), "Introduction: Music and the Sociological Imagination - Pasts and Prospects”, in John Shepherd; Kyle Devine (orgs.), The Routledge Reader on the Sociology of Music. New York: Routledge, 1-22.

Simmel, Georg (1968), "Psychological and Ethnological Studies On Music", in Peter Etzkorn (org.), The Conflict in Modern Culture and Other Essays. New York: Teachers College Press, 98-140.

Straw, Will (2006), "Scenes and Sensibilities", E-Compós, 6, 1-16.

Stubbs, David (2009), Fear of Music. Why People Get Rotbko but Don't Get Stockhausen . Winchester: Zero Books.

Teixeira Lopes, João (2000), "Itinerário teórico em torno da produção dos fenómenos simbólicos”, Sociologia - Revista da Faculdade de Letras da Universidade do Porto, 10, 27-78.

Teixeira Lopes, João (2003), “Da impossibilidade da revolução. Breve contributo sobre Bourdieu e os conceitos de luta e de mudança social”, Fórum Sociológico, 9/10, 87-89.

Vieira de Carvalho, Mário (2007), A tragédia da escuta. Luigi Nono e a música do século $X X$. Lisboa: Imprensa Nacional-Casa da Moeda.

Wacquant, Loïc (2004), Body \& Soul: Notebooks of an Apprentice Boxer. Oxford: Oxford University Press.

Wacquant, Loïc (2005), "Mapear o campo artístico", Sociologia, Problemas e Práticas, 48, 117-123.

Weber, Max (1998), Sociologie de la musique: Les fondements rationnels et sociaux de la musique. Paris: Éditions Métailié.

Weber, William (2003), "Consequences of the Canon. The Institutionalization of Enmity between Contemporary and Classical Music”, Common Knowledge, 9(1), 78-99.

Willis, Paul (1978), Profane Culture. London: Routledge Kegan \& Paul. 
Artigo recebido a 21.07.2015

Aprovado para publicação a 11.01.2016

\section{Gil Fesch}

Instituto de Sociologia da Faculdade de Letras, Universidade do Porto

Via Panorâmica, s/n, 4150-564 Porto, Portugal

Contacto: gilfesch@gmail.com

\section{Towards an Ethnography of New Music: Prologue to a Research Project}

This paper presents a preliminary discussion on the theoretical foundations of an ongoing study. It begins by unravelling the initial approach to the subject of the study - the Casa da Música Remix Ensemble then develops an analytical framework designed to capture recent transformations in the subfield of Portuguese contemporary music, as a means of enriching a much-debated topic - the crisis in new music. It examines four fundamental strands: 1) a brief reassessment of the historic evolution of music sociology; 2) an outline of the theoretical model, based on the dialogue between the key concepts (field and art world); 3) a critical review of the specific literature and the role of ethnography; 4) a brief overview of the research topic and its specific objectives.

Keywords: contemporary music; Howard Becker (1928-); Pierre Bourdieu (1930-2002); sociological theory; sociology of music.

\section{Vers une ethnographie de la musique contemporaine. Prologue pour un projet de recherche}

Le présent article part sur une discussion préliminaire à propos des fondements théoriques qui servent de base à un projet de recherche en cours. Pour ce faire, nous dévoilerons la stratégie d'approche de l'objet d'étude - le Remix Ensemble Casa da Música -, en offrant ainsi un cadre d'analyse qui permette d'aller de l'avant dans la direction d'un portrait du sous domaine de la musique contemporaine portugaise, et qui rende possible une lecture critique de cette crise de la nouvelle musique dont on parle tant. L'exposé se développe autour de quatre axes fondamentaux: 1) brève problématisation de l'évolution historique de la sociologie de la musique; 2) ébauche de modèle théorique, reposant sur une proposition de dialogue entre concepts-clé (domaine et monde artistique);3) révision (très sommaire) de la littérature spécifique et du rôle de l'ethnographie; et 4) analyse de la problématique et définition des objectifs spécifiques.

Mots-clés: Howard Becker (1928-); musique contemporaine; Pierre Bourdieu (1930-2002); sociologie de la musique; théorie sociologique. 
